\title{
SRTC Contribution to EMSP 81898 Annual Report 2003
}

The following describes the SRTC contributions to EMSP 81898 with emphasis on the specific applications to the SRS high level radioactive waste tanks. In particular, the crack growth criteria, constraint effects, and the weld residual stress effects are covered. The write-up consists of two parts: 1) Crack Growth Simulation, and 2) Stress Corrosion Cracking in Weld Residual Stress.

\section{Part I - Crack Growth Simulation}

\section{Slip Line Fracture Mechanics}

The slip line fracture mechanics (SLFM) approach developed at MIT is explored with the finite element analysis of a single edge notched tension (SENT) specimens of A285 steel. The crack growth criterion was based on the slip line solution in terms of crack tip opening angle (CTOA) corresponding to a critical strain ahead of the crack tip.

A single heat of A285 steel with a composition, representative of the 1950's vintage A285 steel, was used in the study. The material properties of the particular heat of A285 steel were used but the strain hardening was neglected (for comparing results with the SLFM prediction, which is based on rigid plasticity). Plane strain SLFM assumes that the material slips at $+/-45^{\circ}$ above and below the crack. This leads to $+/-45^{\circ} \mathrm{CTOA}$ or a plastic strain of 0.577 along the slip line at $+/-45^{\circ}$ emanating from the crack tip. Figure 1 is the plastic strain distribution of an SENT specimen after $1.87 \mathrm{~mm}$ of crack extension under the CTOA fracture criterion $\left(45^{\circ}\right)$. A pair of slip lines with plastic strain 0.577 can be identified ahead of the moving crack tip. The plastic strain in the gray area of Figure 1 is above the critical value of 0.577 , due to the straining of the material behind the growing crack tip. A minor deviation from the prediction of SLFM was resulted, probably due to the continuum effect of the material in the case of a growing crack. 


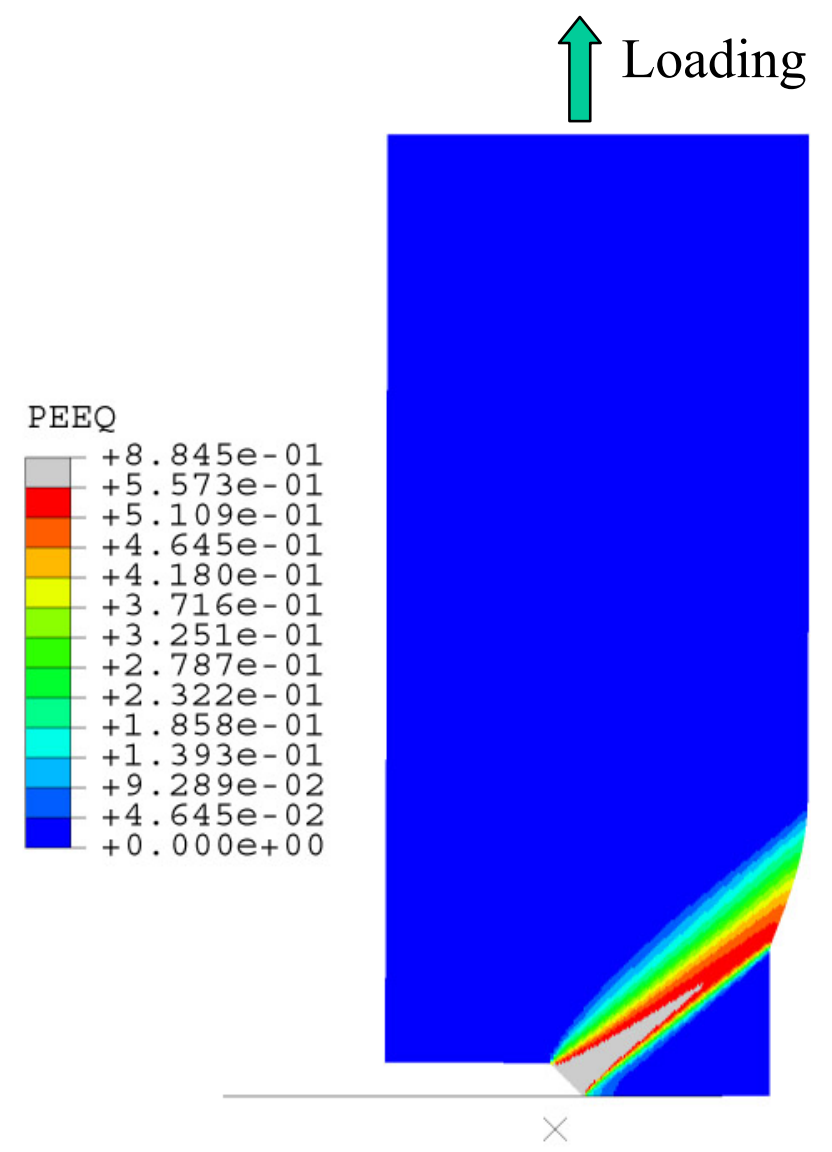

Figure 1 Plastic Strain Distribution of an SENT Specimen after $1.87 \mathrm{~mm}$ of Crack Extension

\section{J-Based Fracture Mechanics}

SRTC fracture test data show the evidence of constraint effects, that is, the fracture toughness is affected by the test specimen size. A series of tests has been carried out with the standard compact tension $(\mathrm{CT})$ specimens $(\mathrm{a} / \mathrm{W} \sim 0.5)$ and with limited number of the single edge-notched bend (SENB) specimens (a/W ranges from 0.3 to 0.7). A twoparameter fracture toughness in terms of J-R curve has been developed for A285 carbon steel, the material of construction of SRS high level radioactive waste tanks.

Crack growth simulation for the SENB specimen has been conducted with the input from fracture test. Figure 2 shows an SENB specimen under load after $5.8 \mathrm{~mm}$ of crack extension. Because of symmetry, only one-half of the specimen and loading pin were modeled. The Mises stress contours were plotted. Higher stress occurred in front of the moving crack tip in the shape of an arc surrounding the elastic core, and on the newly created crack faces.

Figure 3 shows the input of the crack simulation, that is, crack length vs. machine cross-head displacement. The predicted and the actual test data of the load-displacement curves were compared. Close agreement can be seen in Figure 3.

Typical fracture resistance curve (J-R curve) was obtained by ASTM procedures from the test data. Meanwhile, the predicted J-R curve can be obtained by performing contour 
integration with the ABAQUS finite element program. Various integration contours were used. The result shows that ASTM procedure is adequate and it is conservative when compared with the numerical prediction (Figure 4). In addition, the constraint-modified J-controlled crack growth may be still valid.

It is expected that the safety margin will be increased with the use of a J-R curve that is developed specifically for the high level waste tank dimensions and flaw configuration.
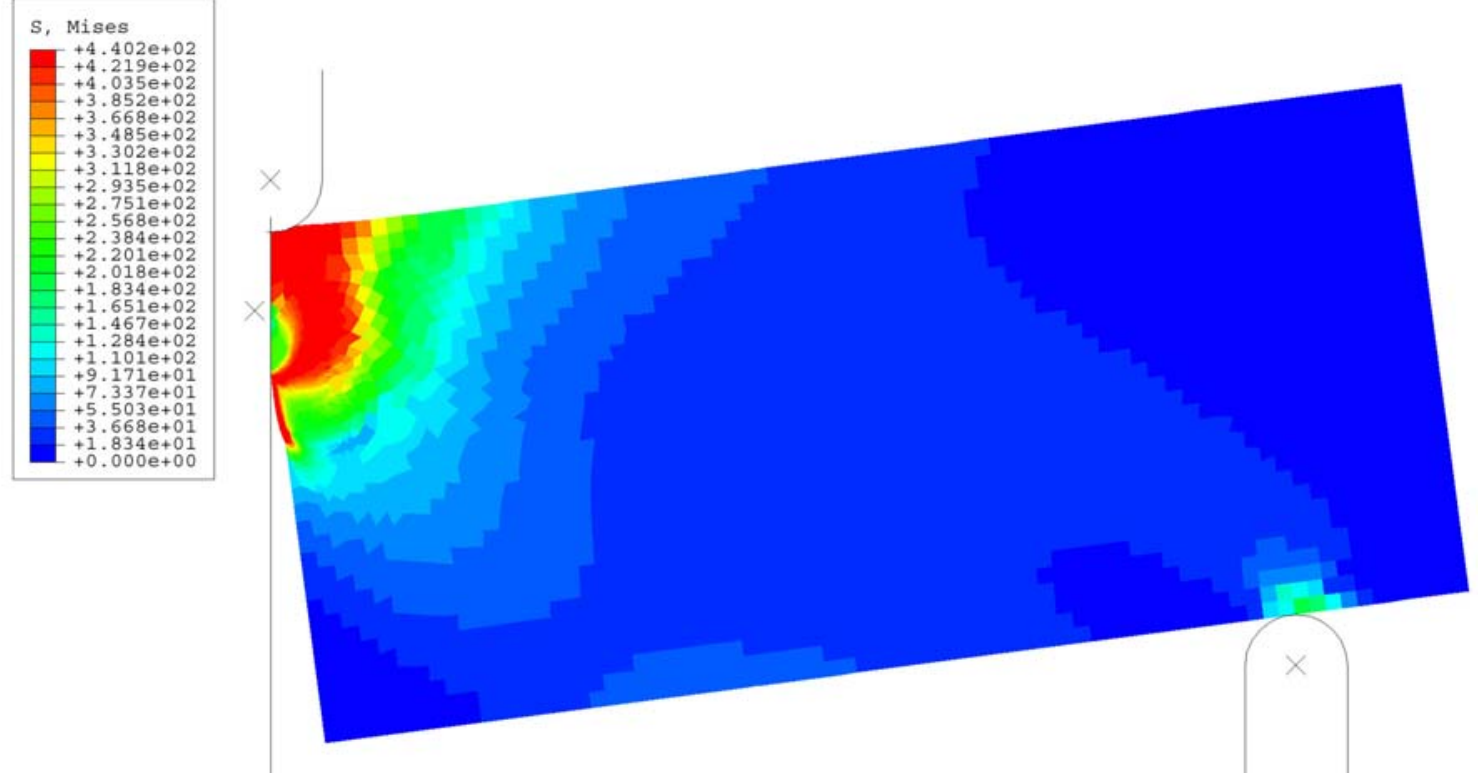

Figure 2 Finite Element Simulation of SENB Fracture testing 


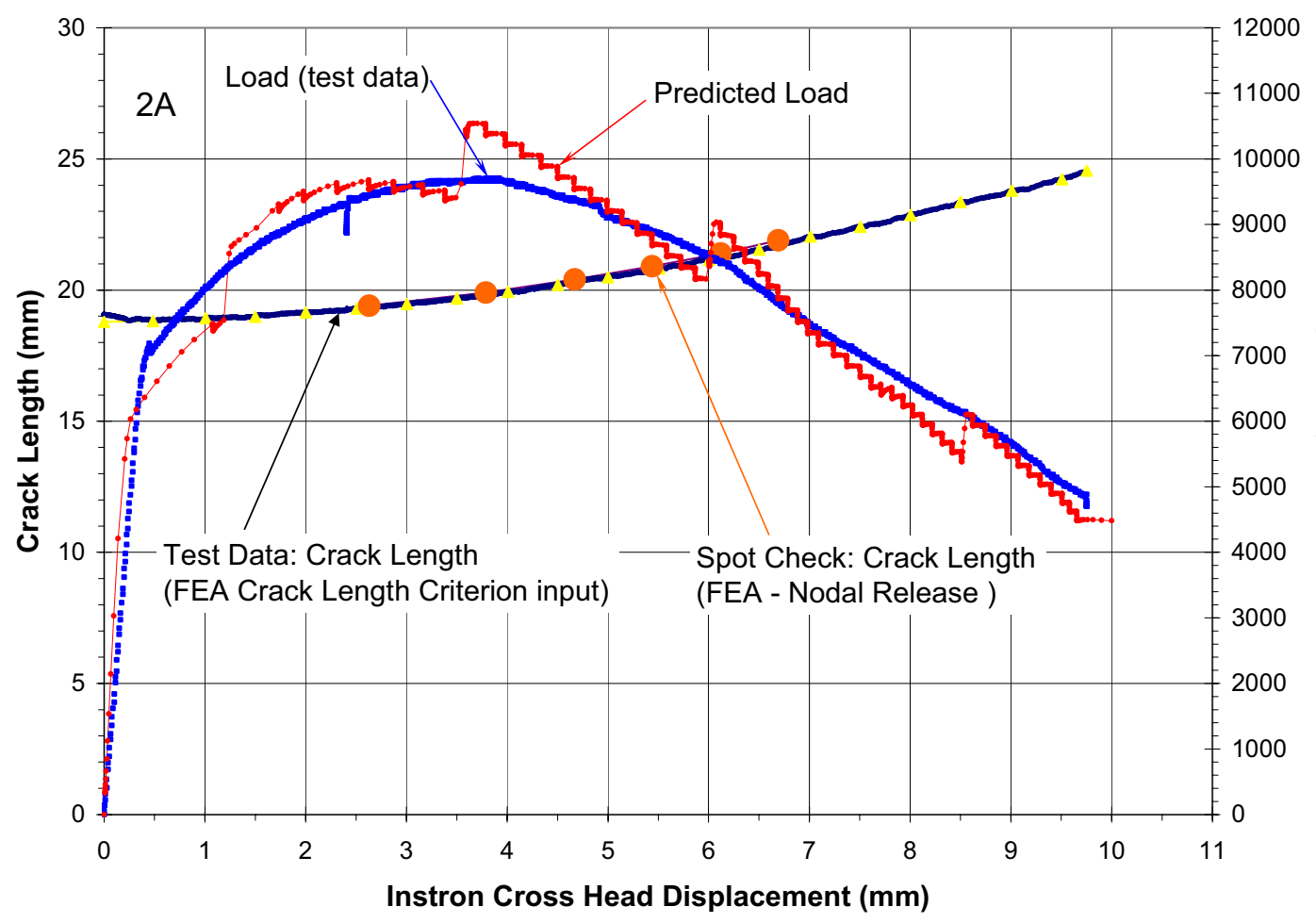

Figure 3 SENB Test Data and Numerical Prediction

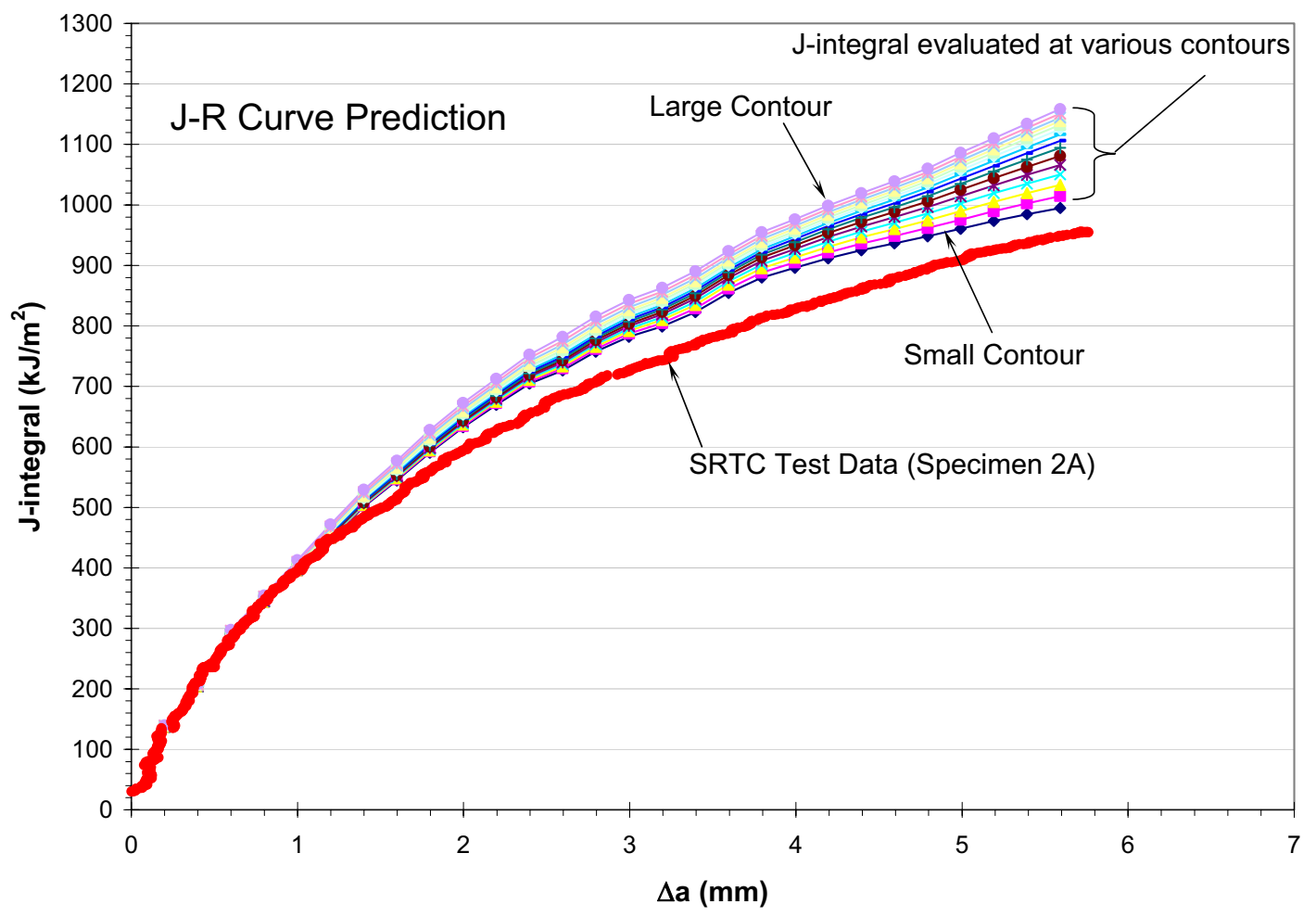

Figure 4 J-R Curve Prediction 


\section{Part II - Stress Corrosion Cracking in Weld Residual Stress Fields}

\section{Introduction}

The materials of construction of the Type I, and II high level nuclear waste tanks at the DOE Savannah River Site and the Single-Shell Tanks at the Hanford site are susceptible to intergranular stress corrosion cracking (IGSCC), at the weld regions. The material of construction is A285 mild steel. The cause of cracking is attributed to nitrate stress corrosion cracking driven by the residual stress due to the welding of the large plates. The stress corrosion cracking (SCC) is observed in or near the weld of a vessel containing a corrosive chemistry. The susceptibility of SCC can be concluded with estimated residual stress distribution and crack growth rate test data. Recent inspection results of the SRS tanks show that cracking may have extended beyond the expected lengths from the weld region.

An experimentation activity is being conducted to investigate the relationship between residual stress and SCC growth in waste tanks. The growth of the SCC in protypic welded tank plate materials will be evaluated. The SCC growth that is measured will be compared to that predicted by evaluating the residual stress driving force of and SLFM for subcritical flaw growth. This will be the first time application of SLFM to described subcritical flaw propagation under a residual stress field. Companion materials of welded plus stress-relieved tank plates will be tested to demonstrate conclusively the benefit of the stress relief treatment.

\section{Fabrication of Welded Carbon Steel Plates}

ASTM A285 Grade B carbon steel was primarily the material of construction of Type I and Type II high level waste tanks that were fabricated in the 1950's. The original vintage of the steel is not available. Based on the chemical composition attributes, A285 Grade C was chosen for the fabrication of the laboratory specimens. A piece of 43 " $\mathrm{x}$ 56" carbon steel plate was purchased from Arch City Steel and Alloy, Inc under WSRC PO\# AC06941A in 1999. The material is 5/8" thick ASTM A285, Grade C, Heat \#R934. Per the Certified Material Test Report, the chemical composition is as follows: $\mathrm{C}-0.075$, $\mathrm{Mn}-0.531, \mathrm{P}-0.008, \mathrm{~S}-0.022, \mathrm{Si}-0.202, \mathrm{Cu}-0.259, \mathrm{Ni}-0.098, \mathrm{Cr}-0.083, \mathrm{Mo}-$ $0.021, \mathrm{Sn}-0.028, \mathrm{Al}-0.002, \mathrm{Nb}-0.001, \mathrm{~V}-0.000$. The mechanical properties are: Tensile strength - $59.0 \mathrm{ksi}$, Yield Strength - $44.0 \mathrm{ksi}$, Elongation - 28\%, 8 inches.

Based on the weld practices of Type I and II waste tanks, shielded metal arc weld (SMAW) was chosen to join two sets of 6" x 12 " plates. Rigid constraint was applied to the plates during welding to simulate large plate welding in the waste tanks to render residual stress as a result of weld pool solidification. This constraint was achieved by fully clamping each weld plate to a backing plate to prevent movement. A $37.5^{\circ}$ beveled edge was machined into the weld plates. Double V grooves were used - three passes were made on the inner groove, the material was allowed to cool, the plates were reclamped, and the remaining three weld passes were completed. Since E6010 filler 
material was used during the SMAW process for Type II, Type III, and Type IIIA waste tanks, it was also used on the lab plates. Two 12" x 12 " specimens were fabricated

(Figure 1).

\section{Figure 1 Welded Plates}

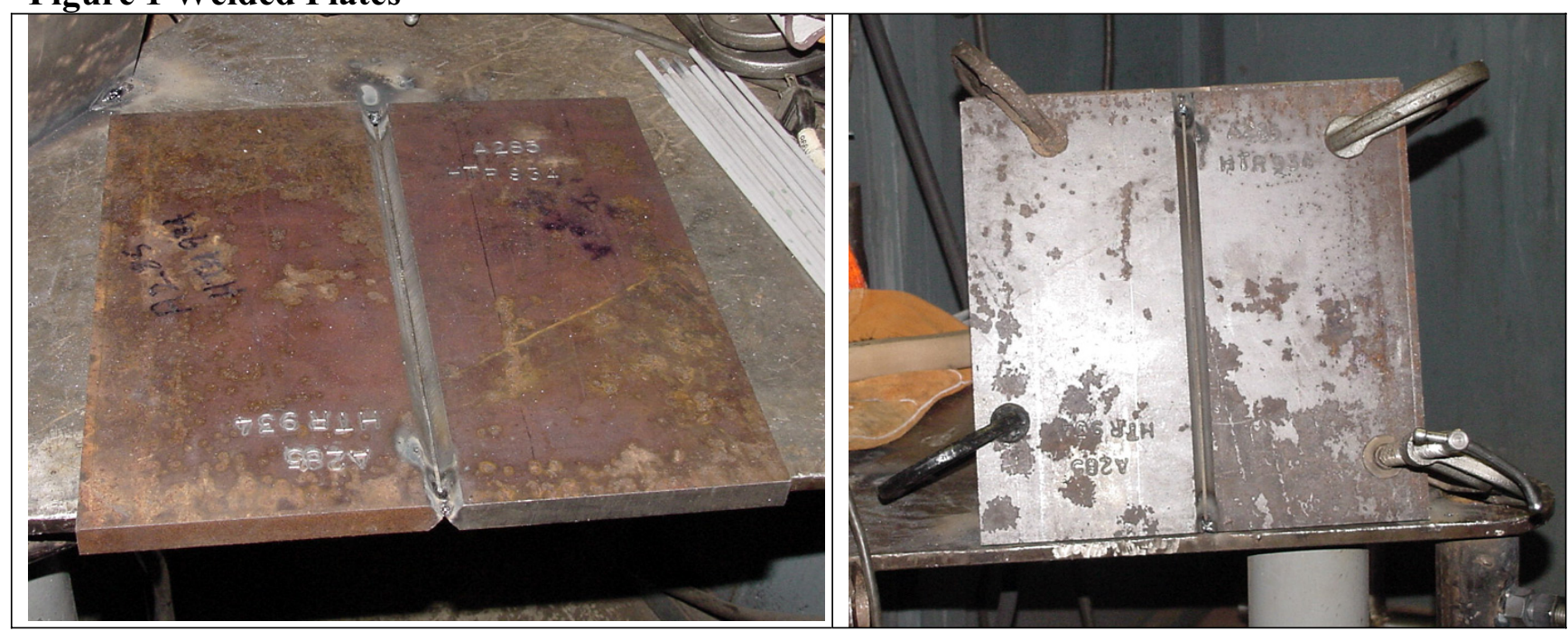

The generally accepted practice for stress relieving carbon steel plate is to heat treat the material at $1100^{\circ} \mathrm{F}$ for one hour using the following recipe: rate of rise - ambient to $600^{\circ} \mathrm{F}$ no restrictions; 600 to $1100^{\circ} \mathrm{F}$ max rate $100^{\circ} \mathrm{F} / \mathrm{hr}$; holding period - minimum 60

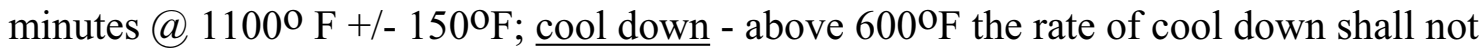
exceed $150^{\circ} \mathrm{F} / \mathrm{hr}$. One set of welded plates was stress relieved according to this process.

\section{Initial Flaws in Welded Plates}

Nine seed flaws were fabricated on each specimen. Three through-plate notches, 0.010 " wide $x$ 1/2" long, were made perpendicular to the weld (V1, V2 and V3). Six partthrough plate notches, 0.006 " wide and $1 / 2$ " long at the surface x 0.25 " deep were made in the heat affected zone (HAZ). Two of the part-through notches were perpendicular to, but not across the weld in the base metal (V4 and V5). The remaining four notches were parallel to the weld and on the edge of the weld in the base metal (P1, P2, P3 and P4). Identical notches were fabricated in each plate (Figure 2). 
Figure 2 Fabricated Notches in Weld

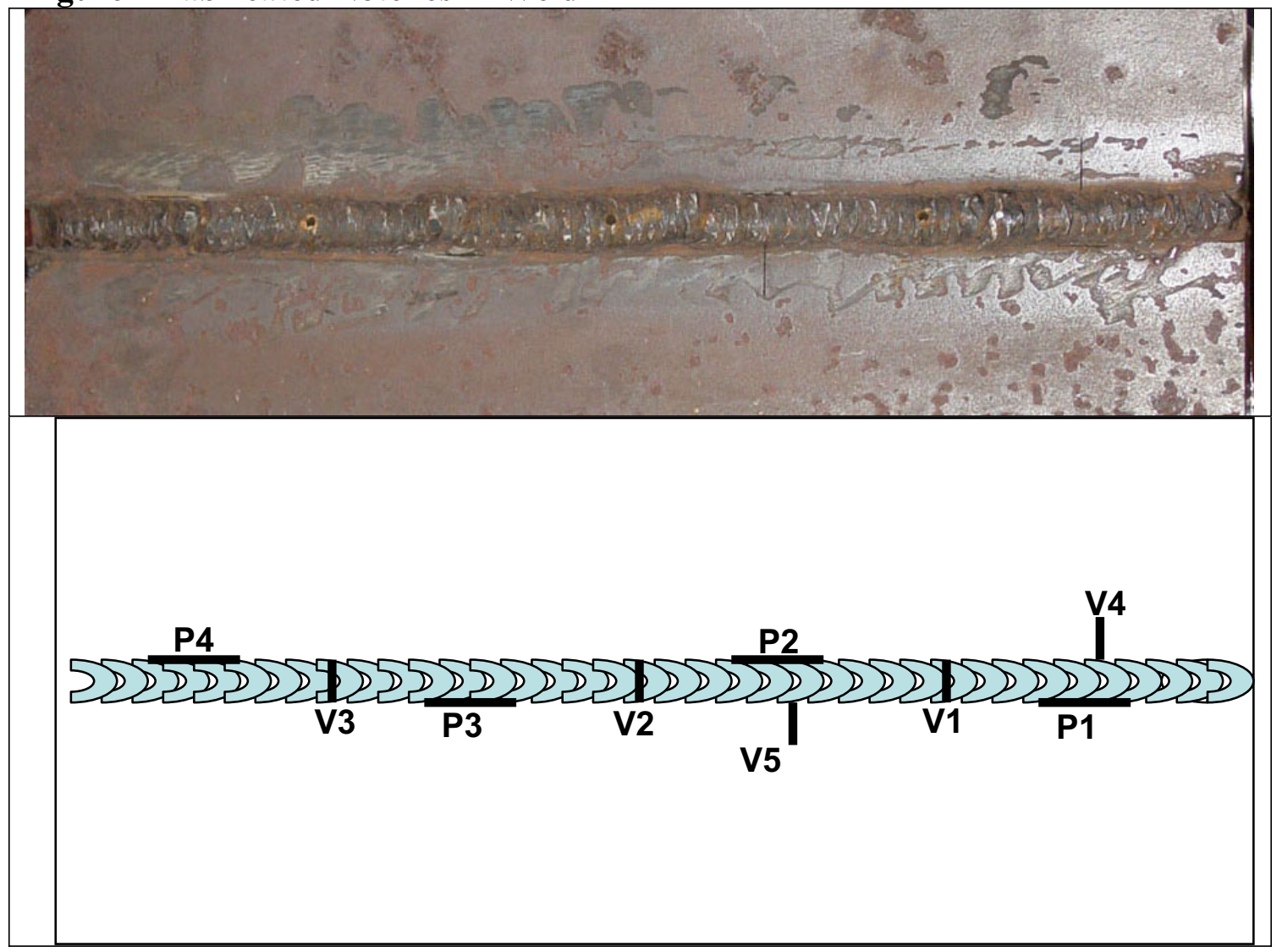

\section{- Flaw Production Details}

Metal Samples Company fabricated the nine notches using the wire-EDM (Electrical Discharge Machining) technique.

\section{Initial Flaw Characterization/sizing}

The NDE effort included examination with digital radiography, automated ultrasonic weld inspection and manual, ultrasonic planar flaw sizing techniques. Manually operated ultrasonic flaw sizing techniques were also utilized to evaluate the notches to provide a baseline for measuring any SCC that may be detected. These techniques were used to get precise measurement of length and depth. The primary manual sizing technique utilized is known as flaw tip diffraction, relative arrival time technique. Lengths were also confirmed with a WSY-70 technique.

Table 1 indicates the initial flaw lengths and depths as characterized by manual ultrasonic testing. 
Table 1 UT Initial Flaw Length and Depth

UT Data Heat Treated Plate

\begin{tabular}{|l|c|c|}
\hline $\begin{array}{l}\text { Indication/ } \\
\text { Method/ } \\
\text { Orientation }\end{array}$ & $\begin{array}{c}\text { Flaw } \\
\text { length }\end{array}$ & $\begin{array}{c}\text { Thru } \\
\text { Wall } \\
\text { Depth } \\
\text { Inches }\end{array}$ \\
\hline $\begin{array}{l}\text { P1 Manual } \\
\text { Parallel }\end{array}$ & 0.8 & 0.27 \\
\hline $\begin{array}{l}\text { P2 Manual } \\
\text { Parallel }\end{array}$ & 0.8 & 0.25 \\
\hline $\begin{array}{l}\text { P3 Manual } \\
\text { Parallel }\end{array}$ & 0.7 & 0.255 \\
\hline $\begin{array}{l}\text { P4 Manual } \\
\text { Parallel }\end{array}$ & 0.6 & 0.27 \\
\hline $\begin{array}{l}\text { V4 Manual } \\
\text { Perpendicular }\end{array}$ & 0.9 & 0.25 \\
\hline $\begin{array}{l}\text { V5 Manual } \\
\text { Perpendicular }\end{array}$ & 0.8 & 0.28 \\
\hline
\end{tabular}

UT Data Non-Heat Treated Plate

\begin{tabular}{|l|c|c|}
\hline $\begin{array}{l}\text { Indication/ } \\
\text { Method/ } \\
\text { Orientation }\end{array}$ & $\begin{array}{c}\text { Flaw } \\
\text { Length }\end{array}$ & $\begin{array}{c}\text { Thru } \\
\text { Wall } \\
\text { Depth } \\
\text { Inches }\end{array}$ \\
\hline $\begin{array}{l}\text { P1 Manual } \\
\text { Parallel }\end{array}$ & 0.7 & 0.26 \\
\hline $\begin{array}{l}\text { P2 Manual } \\
\text { Parallel }\end{array}$ & 0.7 & 0.25 \\
\hline $\begin{array}{l}\text { P3 Manual } \\
\text { Parallel }\end{array}$ & 0.8 & 0.27 \\
\hline $\begin{array}{l}\text { P4 Manual } \\
\text { Perpendicular }\end{array}$ & 0.7 & 0.27 \\
\hline $\begin{array}{l}\text { V4 Manual } \\
\text { Perpendicular }\end{array}$ & 0.8 & 0.225 \\
\hline $\begin{array}{l}\text { V4 Manual } \\
\text { Perpendicular }\end{array}$ & 0.8 & 0.27 \\
\hline
\end{tabular}

\section{$\underline{\text { Immersion Test }}$}

An immersion tank was fabricated by welding 304 stainless steel plates. The tank is approximately three (3) inches wide and 15 inches deep, and holds approximately three (3) gallons. A thermal wrap blanket will be placed around the outside of the tank to heat the contents. The 5 Molar Sodium Nitrate will be used as the simulate waste solution, and will be heated to $90^{\circ} \mathrm{C}$. Thermocouples will be placed in the solution to monitor and regulate the solution temperature. The immersion testing will begin in late July-August 2003 following completion of the test authorization package. 